
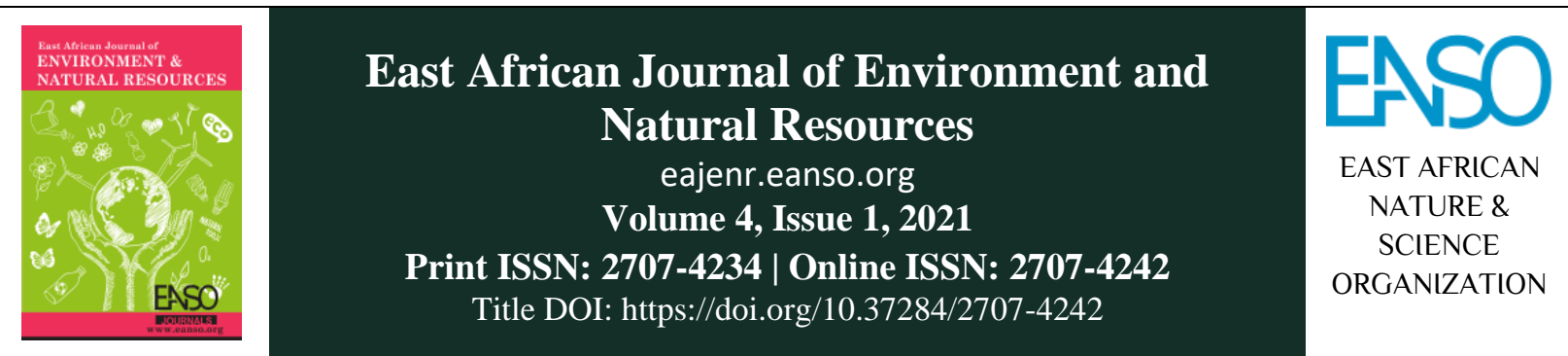

Original Article

\title{
Elephant Population Status, Distribution and Conservation Threats in Kibale National Park, Uganda.
}

\author{
Aleper Daniel $^{1 *}$, Andama Edward ${ }^{2} \&$ Adriko Kenned $^{2}$ \\ ${ }^{1}$ Gulu University Constituent College Moroto P. O. Box 161, Moroto Uganda. \\ ${ }^{2}$ Biology Department, Faculty of Science and Education, Busitema University, P. O. Box 236, Tororo Uganda. \\ ${ }^{3}$ Business Summit Africa Plot 19. 20 and 21 Mulwana Road Industrial Area, Kampala Uganda. \\ *Correspondence email: aleperdaniel@gmail.com.
}

Article DOI: https://doi.org/10.37284/eajenr.4.1.499

\section{Date Published: ABSTRACT}

08 December 2021 This study focused on the estimation of the African elephant population, distribution, and conservation threats in Kibale National Park (KNP) from

Keywords: August 2019 to February 2020. The objectives of the study were to: generate population estimates, distribution and assess threats to the conservation of

African Elephant, elephants. The line transect method based on the dung pile count density from

Kibale National line transect, dung decay, and defecation rates were used to estimate the elephant

Park, population. The density was calculated by multiplying the decay rate with the

Population, ratio of dung density to defecation rates. The overall elephant population was

Conservation estimated at 566.27 (95\% Confidence limits 377.24-850.02). This was a slow

Threats, Human- increase from 393 recorded in 2005 to 566 animals in 2019. Elephants were

Elephant Conflicts widely distributed within the park and these pose challenges such as increasing human-elephant conflicts. With a steady increase in the elephant population and seasonal movements out of the park, there is a need to continuously monitor elephant population growth and ranging behaviour vis-a-vis available habitat range and how this impacts ecosystem dynamics and human-elephant conflicts.

\section{APA CITATION}

Daniel, A., Edward, A., \& Kennedy, A. (2021). Elephant Population Status, Distribution and Conservation Threats in Kibale National Park, Uganda. East African Journal of Environment and Natural Resources, 4(1), 68-78. https://doi.org/10.37284/eajenr .4.1.499

\section{CHICAGO CITATION}

Daniel, Aleper, Andama Edward, \& Adriko Kennedy. 2021. "Elephant Population Status, Distribution and Conservation Threats in Kibale National Park, Uganda". East African Journal of Environment and Natural Resources 4 (1), 68-78. https://doi.org/10.37284/eajenr.4.1.499.

68 This work is licensed under a Creative Commons Attribution 4.0 International License. 
HARVARD CITATION

Daniel, A., Edward, A., \& Kennedy, A. (2021) "Elephant Population Status, Distribution and Conservation Threats in Kibale National Park, Uganda", East African Journal of Environment and Natural Resources, 4(1), pp. 68-78. doi: 10.37284/eajenr.4.1.499.

\section{IEEE CITATION}

A. Daniel., A. Edward., \& A. Kennedy, "Elephant Population Status, Distribution and Conservation Threats in Kibale National Park, Uganda", EAJENR, vol. 4, no. 1, pp. 68-78, Dec 2021.

\section{MLA CITATION}

Daniel, Aleper, Andama Edward, \& Adriko Kennedy. "Elephant Population Status, Distribution and Conservation Threats in Kibale National Park, Uganda". East African Journal of Environment and Natural Resources, Vol. 4, no. 1, Sep 2021, pp. 6878, doi:10.37284/eajenr.4.1.499.

\section{INTRODUCTION}

The African Elephant (Loxodonta africana, Blumenbach) remains on the red list of threatened species (IUCN, 2021). Elephant contribution to the maintenance of wild ecosystems and hence the provision of chance for other wildlife's survival (Campos-Arceiz \& Blake, 2011) can never be overemphasized. From history, Elephants ranged throughout Uganda; however, today their range of habitats has contracted to the few protected areas scattered and unconnected across Uganda. This has been due to the growth in human population and activities, coupled with the increased demand for arable land and settlement which significantly reduced the viable habitats for elephants (Naughton et al., 1999). In addition to the poaching for ivory, human-elephant conflict (HEC) is increasingly emerging as one of the key challenges faced by protected area managers. These and other conservation threats can only be sustainably mitigated if the population status, distribution of elephant population are ascertained and a long-term system is established to monitor and develop sustainable solutions to manage the challenges.

The status of the elephant population in KNP has not been ascertained in recent times. It is thus important to establish how many elephants are in any given population and whether the population in question is increasing, decreasing, or stable (Kangwana, 1996b). Wing and Buss (1970) made a comprehensive population study of elephants in KNP, documenting the annual and seasonal distribution of elephants, forage plant species, and relative quantities of forage species eaten. Except for the estimates made by Wing and Buss (1970), there has been no definitive census focusing on estimating elephant numbers in KNP. The wildlife population studies in KNP have primarily focused on primates, especially chimpanzees with elephants considered as secondary. The recent elephant population estimates were based on projections, not field-based data estimates. These estimates need to be complemented with rigorous methods. This study was specifically designed to (i) estimate population, (ii) distribution of Elephants, and (ii) identify threats to the conservation of elephants.

\section{MATERIALS AND METHODS}

\section{Study area}

The study was undertaken in Kibale National Park (KNP) (Figure 1), which is the third-largest forest national park in the country. KNP has a wide altitudinal range, rising from $1,110 \mathrm{~m}$ in the south to $1,590 \mathrm{~m}$ in the extreme North, and occupies undulating terrain on the main Ugandan plateau draining in a southerly direction. Two main rivers, Mpanga and Dura flow through the park and drain into Lake George. KNP is considered the most extensive tract of relatively undisturbed forest remaining at this altitude in Uganda (Howard, 1991). First gazetted as Kibale Crown Forest in 1930 , its size and continuity of forest habitat make Kibale a prime habitat for biodiversity conservation. The sole objective then was exploitation for timber and charcoal until the mid-eighties when logging was stopped. By the early nineties' conservation objectives increased in importance and subsequently, Kibale Forest Reserve was gazetted as a National Park in 1993 and was transferred to Uganda Wildlife Authority (UWA) after amalgamation with Kibale Game Reserve/Corridor (termed as Dural corridor) to form the Kibale National Park. Its primary purpose was biodiversity 
East African Journal of Environment and Natural Resources, Volume 4, Issue 1, 2021

Article DOI: https://doi.org/10.37284/eajenr.4.1.499

conservation with the secondary objective of

providing local and national socio-economic

benefits through specific sustainable activities.

Figure 1: Location of Kibale National Park

70 | This work is licensed under a Creative Commons Attribution 4.0 International License. 
East African Journal of Environment and Natural Resources, Volume 4, Issue 1, 2021

Article DOI: https://doi.org/10.37284/eajenr.4.1.499

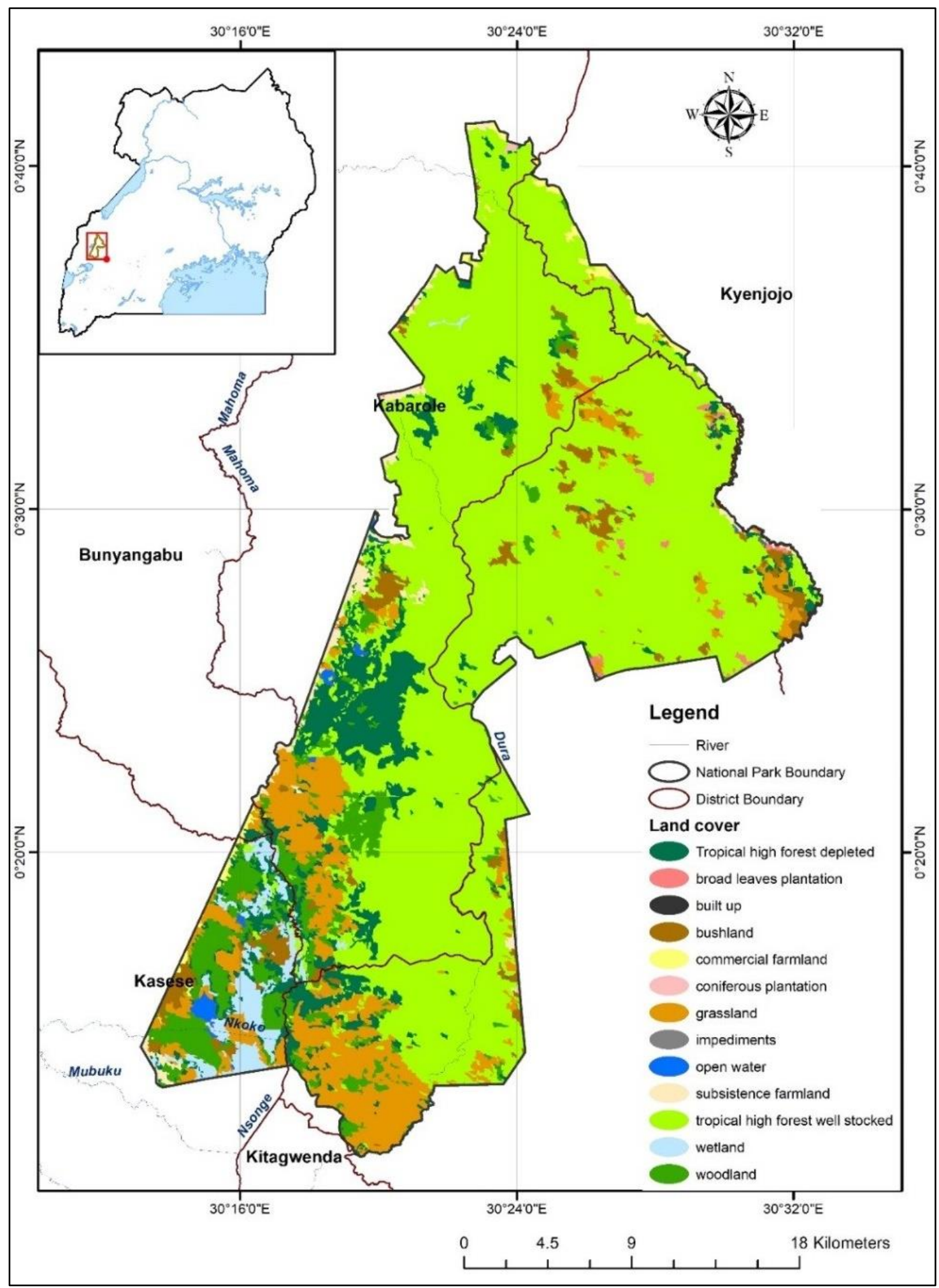

KNP is mainly a medium-altitude transitional moist evergreen forest with characteristics of both dry tropical and wet tropical rain forests. The major habitat types include swamps, forests, and

grasslands, which form a mosaic of vegetation. The grassland communities are similar to those found in high rainfall areas in Uganda. The dominant species are Pennisetum purpureum, Imperata cylindrica,

71 This work is licensed under a Creative Commons Attribution 4.0 International License. 
East African Journal of Environment and Natural Resources, Volume 4, Issue 1, 2021

Article DOI: https://doi.org/10.37284/eajenr.4.1.499

and Cymbopogon afronardus. These generally occupy hilltops and are probably a result of human settlement and bush fires.

The forest cover is broadly classified as moist evergreen in the north and moist semi-deciduous in the south. In the central part, the high forest is a mixture of deciduous and evergreens with evergreen tree species being predominant. Trees rise to over $55 \mathrm{~m}$ and exhibit a semi-closed canopy of stratified tree crowns. Important Fauna includes threatened and near-threatened species such as Loxodonta africana (elephants), Panthera pardus (leopard), Pan troglodytes (chimpanzee), Procolobus badius (red colobus monkey), and Cercopithecus l'hoesti (L'Hoesti monkey). Kibale is well known for being home to thirteen species of non-human primates and harbours one of the most viable populations of red colobus monkeys in Uganda (Struhsaker \& Ting, 2020). The chimpanzees are the main tourist attraction in the park. KNP is listed as one of the thirty Important Bird Areas in Uganda, with at least 372 species of birds, occurring in 58 families (Byaruhanga, 2001).

\section{Data Sampling and Analysis}

Elephants that inhabit forests are rarely seen due to the dense vegetation, however, their signs are conspicuous. Under this situation, we estimated elephant population size using an indirect method based on dung pile counts along transects, corrected for variables such as dung deposition rate, decay rate, and rainfall in the two months before the count (Barnes \& Jensen, 1987); (Barnes et al., 1997). Hedges et al. (2013) reported that the results from indirect methods are comparable to those obtained using other methods. Dung counts have been recommended to be the most practical means of estimating numbers and distribution of forest elephants (Barnes et al. 1997). During preliminary/reconnaissance different sites of the study, areas were visited and the study area was stratified based on the vegetation. Eighteen (18) transects (fig. 2) were then laid based on the strata, covering $63 \mathrm{~km}$ length. Transect distribution ensured a proportionate representation of various vegetation types in the study area. The transect length was variable and averaged $3.5 \mathrm{~km}$, depending on the terrain and habitat type.

Figure 2: Locations of the transects in the study area 


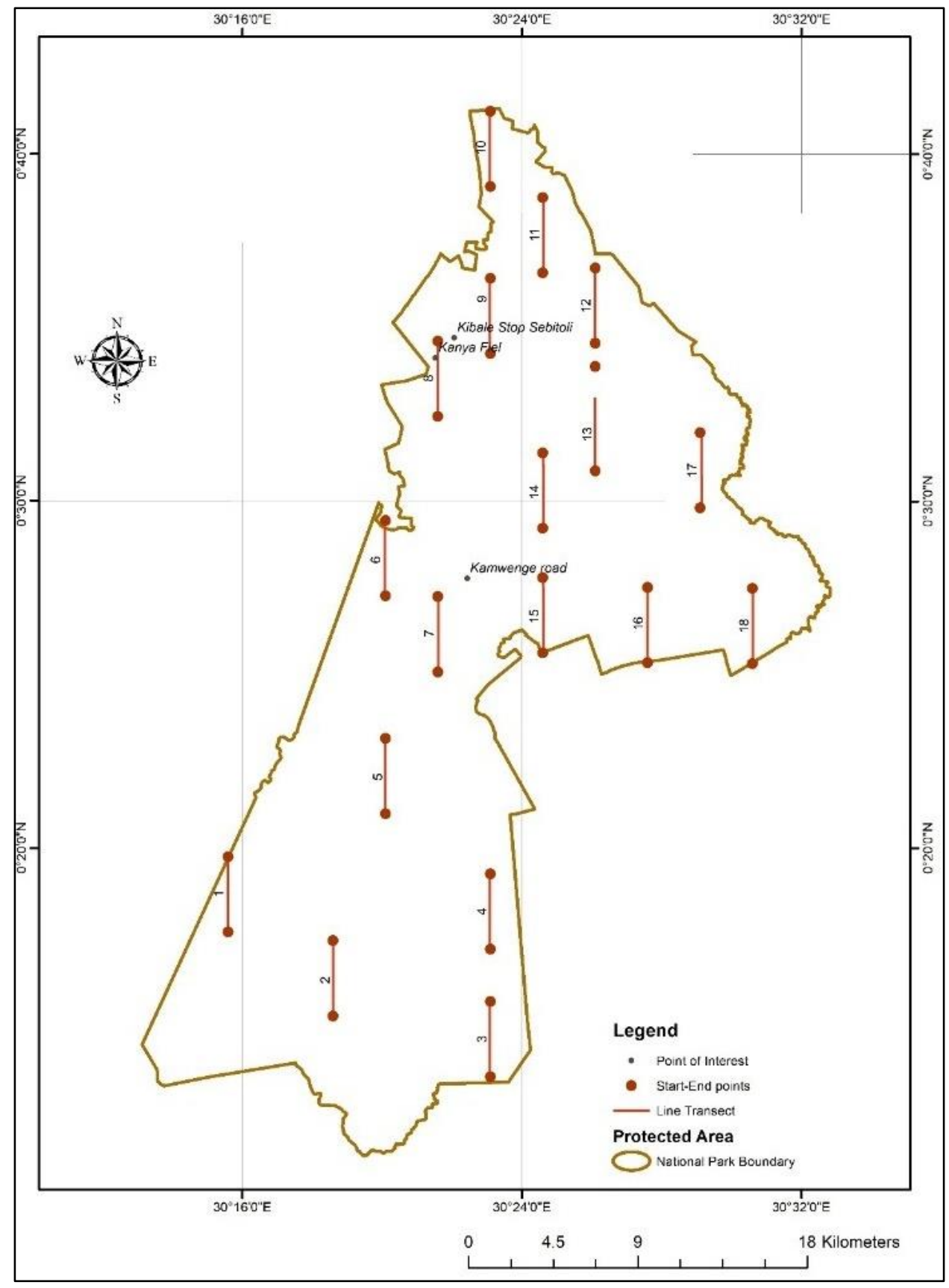

Fieldwork for this study was undertaken during the rainy season from September 2019 to February 2020. The fieldwork team comprised of a leader working with trained research assistants consisting of UWA staff and selected individuals from the local community who had good knowledge of the study site. Elephants sighted, type of habitat, dung piles, or any other elephant spoors were counted and recorded in line transect and stratum/block. The counts were all done on foot, starting between 06:30 and 10:00 hours. Data were collected from only one transect per day to minimize fatigue that would lead to biasness. Each team walked quietly along the transect line with the lead person often opening the transect using a machete knife. Groups of dung pile spotted on both sides of the transect line were counted and the perpendicular distance from the observation to the centreline of the transect was measured with a steel or fibreglass tape measure $(5$ $\mathrm{m}$ and $50 \mathrm{~m}$ ) as well as a range finder (ultrasonic Distance Estimator Model: Mastech (MS6450) range $0.6-15 \mathrm{~m})$. The locations of dung piles were

73 This work is licensed under a Creative Commons Attribution 4.0 International License. 
recorded using Global Positioning System (GPS) equipment (Garmin GPS e-Trex 30x and Garmin GPSmap64s). The total distance covered by the transect line walked was recorded using the GPS waypoint measurements for each transect covered. The team used the dung classification proposed by Barnes and Jensen (1987) further modified by
Barnes (1996) and later modified by the MIKE (Monitoring the Illegal Killing of Elephants) system (Hedges, 2012). The dung Categorization of boli adopted and modified from MIKE (Monitoring the Illegal Killing of Elephants) system for dung classification Hedges (2012) and Barnes (1996) (Table 1) was used.

Table 1: Categorization of boli (adopted and modified from MIKE system for dung classification

\begin{tabular}{ll}
\hline Category & Description \\
\hline A & All boli are intact (very fresh, moist, with odour) \\
B & One or few boli intact (fresh but dry, no odour) \\
C & No intact boli (fibres are held together by faecal materials) but are still recognizable as boli \\
D & No boli intact (All boli completely disintegrated) no coherent fragments present. \\
E & Decayed to the stage where it would be unlikely to see any faecal matter. \\
\hline
\end{tabular}

Source: (Hedges (2012) and Barnes (1996b)

Elephant dung piles observed in the category/stage E were not used in the population data analysis and while all detections were used for mapping distribution (Vanleeuwe, 2010). The dung detection probability $\mathrm{f}(0)$ of the observations was obtained and used to calculate the population density of the observations. The $\mathrm{f}(0)$ is an estimate of the reciprocal of the effective strip width (ESW) of any given line transect. The ESW is equal to the number of observations beyond the ESW that are detected (Buckland \& Elston, 1993). The population density D was computed using R. DISTANCE (Laake et al., 1994) statistical programme. It uses the perpendicular distances recorded and the total length for each transect to estimate the density of dung-piles, $\mathrm{D}$, using the formula given below:

$$
\mathrm{D}=\frac{n f(0)}{2 L}
$$

Where $\mathrm{n}$ represents the number of dung piles observed while L represents the overall length of the transect in which the observations were recorded. The data analysis took into consideration at least three strata (categorized according to the vegetation type) separately which were then combined to give an overall estimate for the whole study area (Norton-Griffiths, 1978). The assumptions required for the Distance statistical programme (Fewster et al., 2005) were taken into consideration. The population (E) of elephants was calculated from the dung-pile density (Y), the defecation rate (D), and the decay rate (r) by the equation (McClanahan, 1986; Barnes \& Jensen, 1987): The dung defecation and degradation rates undertaken earlier in the same habitat condition at Kibale National Park were used. The individual variances of $\mathrm{Y}, \mathrm{r}$, and $\mathrm{D}$ each contribute to the adjustment of E (Barnes, 1993).

$$
E=\frac{Y r}{D}
$$

The density of elephant dung was converted into animal density using the following formula:

$$
\text { Elephant density (No./sq km) }=\frac{D}{D R} \times D D R
$$

Where $\mathrm{D}=$ Dung Density; DR= Defecation Rate and $\mathrm{DDR}=$ Dung Decay rate.

The distribution and the ranging areas of elephants were obtained through recording of GPS point locations of the different sites where evidence of elephant spoors was recorded such as dung droppings, vegetation damage, footmarks, wallowing sites, and crop damage sites. Spatial analyses for the distribution of elephant groups were conducted following Hickey et al. (2019) using ESRI ArcGIS 10.6.1.

Threats to elephant populations were documented through recordings of hunting evidence, trapping, evidence of elephant carcasses or skeletons recorded or reported during the study. In addition, evidence of crop raids/depredation within the community that would expose the elephants to attack by the community was also compiled. The existing mitigation measures to human-elephant 
conflicts being undertaken by the park and local communities were documented. Additional information on distribution and threats to elephants was obtained from the park ranger patrol cover records of the protected area system over the last one to two years.

\section{RESULTS}

\section{Population Status}

During the transect walks four (4) elephant families were physically encountered, totalling 17 individuals and giving a mean group size of 4.25, excluding the lone males that were observed. The relative encounter rates of elephant spoors are shown in Table 2.

Table 2: Encounter rates elephant and dung piles in KNP (total distance covered was $86.8 \mathrm{Km}$ )

\begin{tabular}{lllll}
\hline $\begin{array}{l}\text { Protected } \\
\text { area }\end{array}$ & $\begin{array}{l}\text { Total encounters } \\
\text { (individuals/group) }\end{array}$ & $\begin{array}{l}\text { Encounter } \\
\text { rate elephants } \\
\text { km walked }\end{array}$ & $\begin{array}{l}\text { The encounter } \\
\text { of the dung pile }\end{array}$ & $\begin{array}{l}\text { Encounter rates of } \\
\text { dung pile per Km } \\
\text { walked }\end{array}$ \\
\hline KNP & 7 & 0.004 & 396.000 & 4.560 \\
\hline
\end{tabular}

Based on the distance package analysis, the elephant population was estimated at $566.27 \pm 236 \quad(95 \%$ Confidence limits 377.24-850.02). This result showed that the elephant population in KNP increased slowly and steadily since the 2005 estimate of 393 (UWA, 2005). Fig. 3. shows the trends in the population of elephants in KNP. KNP elephant population experienced a reduction between the 1960s to 2001 and thereafter it recorded a generally steady increase between 2001 up to 2019 , more than doubling in about 2 (two) decades. In general, there was a steady elephant population recovery from the year 2000 onwards.

Figure 3: Trends in elephant population growth in KNP from 1962-2019

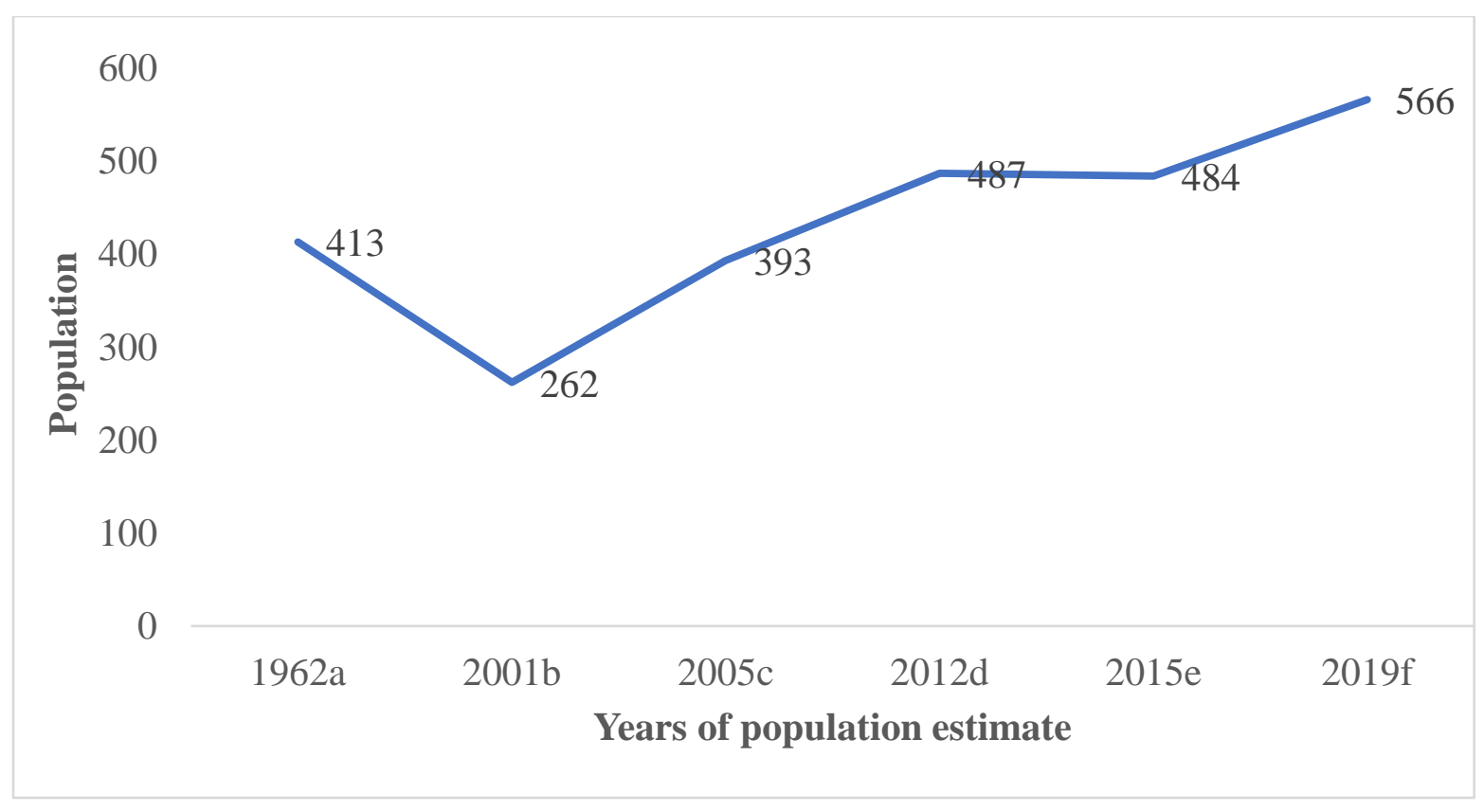

$a \& c$ Wanyama (2005), $b \& d$ UWA (2016), e Blanc, J. J. (2007), f This study. 


\section{Elephant Distribution}

The range of elephant foraging areas expanded in KNP (Figure 4). From the initial distribution map, elephants were more concentrated in the northern sector compared to the southern sector. High elephant densities were observed around Sebitoli, Ngogo research areas, and areas close to Isunga. We recorded more activity of elephants in more open habitats (in particular the grassland areas) than in closed forest sites. Moderate densities were recorded in southern areas such as Nyabitusi and Kakooga and areas near the Dura corridor which were mainly wooded grassland. The trenches were constructed in some areas to limit/prohibit elephant movement into the community to raid crops. The areas with trenches included Nyabitusi, Busiriba, and Nyabweya parishes. Comparing previous elephant distribution patterns over a 15 -year period (Figure $5 a, b \& c$ ) there has not been a particular fixed pattern of distribution. For example in 2005 UWA (2005) (Figure 5a) reported higher elephant densities at the central and eastern parts of the park. In 2016 (UWA, 2016) reported slightly higher densities in the eastern part of the park, especially in Nyaibanda areas and central areas of Mpokya, Kanyanchu (Wilderness zone), and Mainaro. Moderate densities were also recorded in Sebitoli areas and southern parts of the park and near the Dura corridor (open savanna areas) as indicated in Figure $5 b$. In the current study, higher densities were recorded in the central to the northern sector than the southern sector Figure $5 c$.

\section{Figure 4: Relative distribution of elephants in KNP}

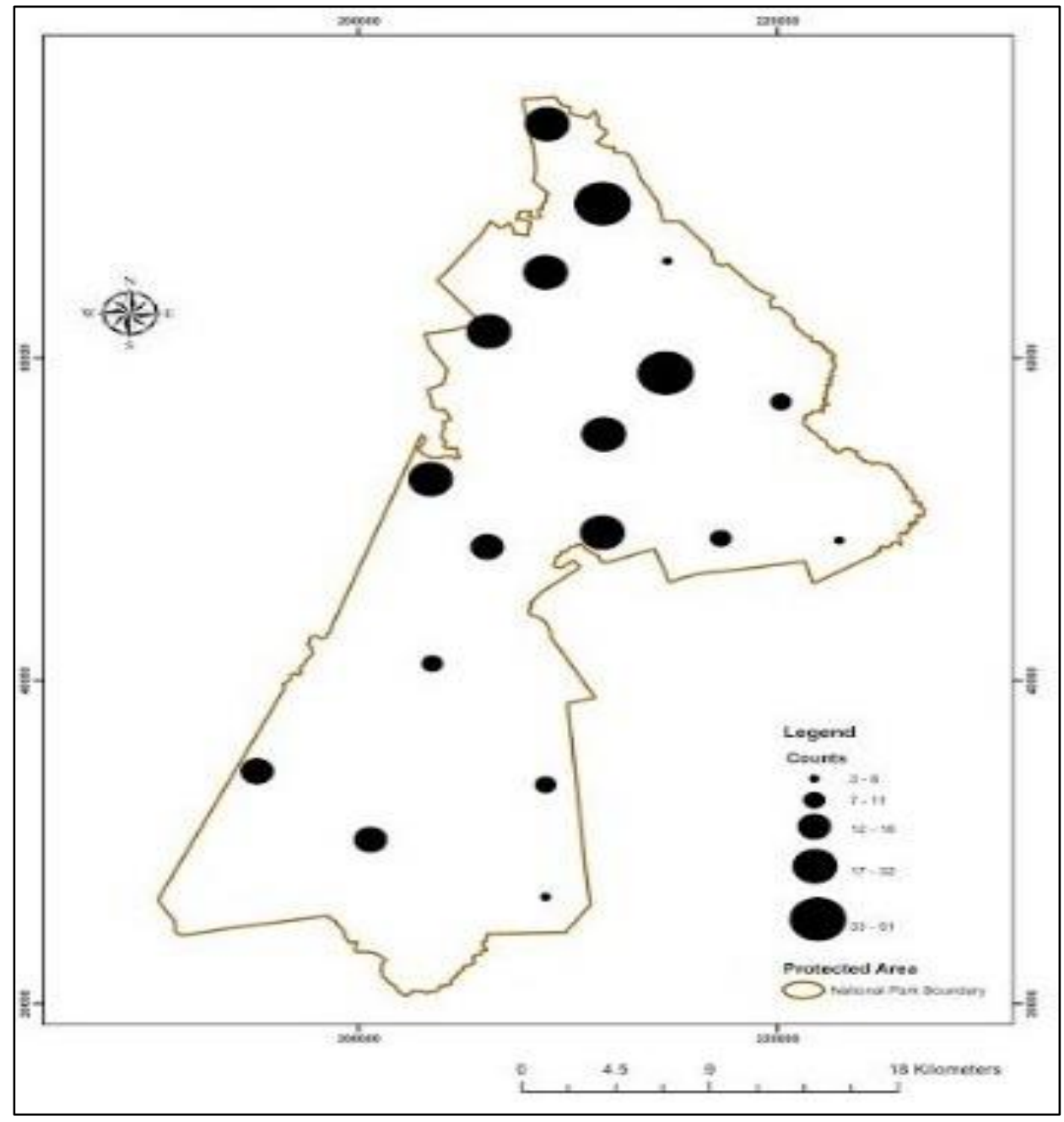

76 | This work is licensed under a Creative Commons Attribution 4.0 International License. 
Figure 5: Distribution pattern of elephant signs over 15 years in KNP.

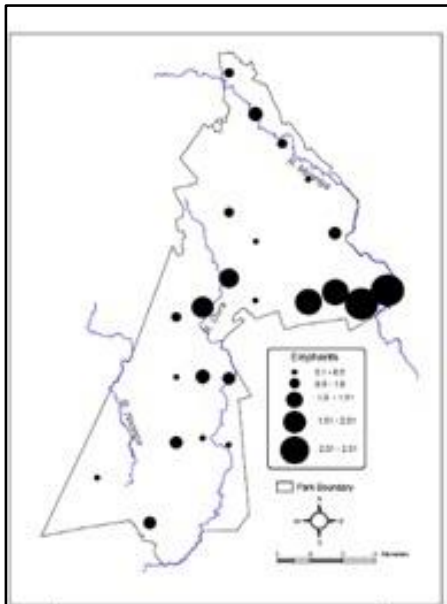

(a) Wanyama 2005

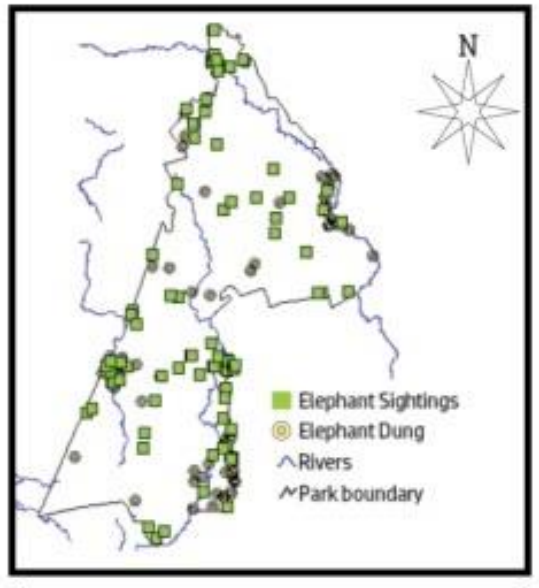

(b) UWA monitoring report 2016

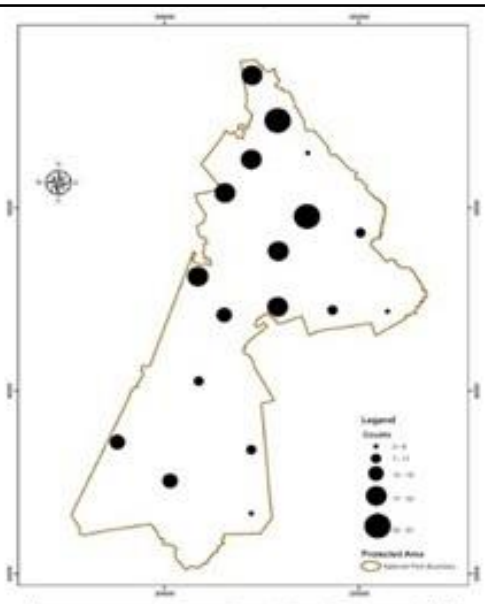

(c) Current study 2019

\section{Threats to Elephant Conservation}

Three snares and one pit trap were recorded along the transects covered, mainly from the areas to the South Western part (near Mobuku Government prison) in Kasese district Figure 6a. Many of the traps recovered may not specifically target elephants but rather other relatively smaller animals such as buffaloes, antelopes among others. Pitfall traps (Figure 6b) can kill large animals such as young elephants if they cannot walk out of the trench. This study noted that in the last two decades or so four elephants were reported to have died in the park. From the recovered skeletons, one victim was young juvenile of about 7 years of age as shown by molar teeth measurements. Such a young elephant could have been killed by a snare or disease. This pattern of recorded mortality, among other factors may affect the population growth of elephants in KNP. According to the park management, snares continue to be regularly recovered from the park, especially in the areas which are far from ranger camps or less regularly patrolled.

Figure 6: Snares (a) and pitfall trap (b) recorded in KNP.

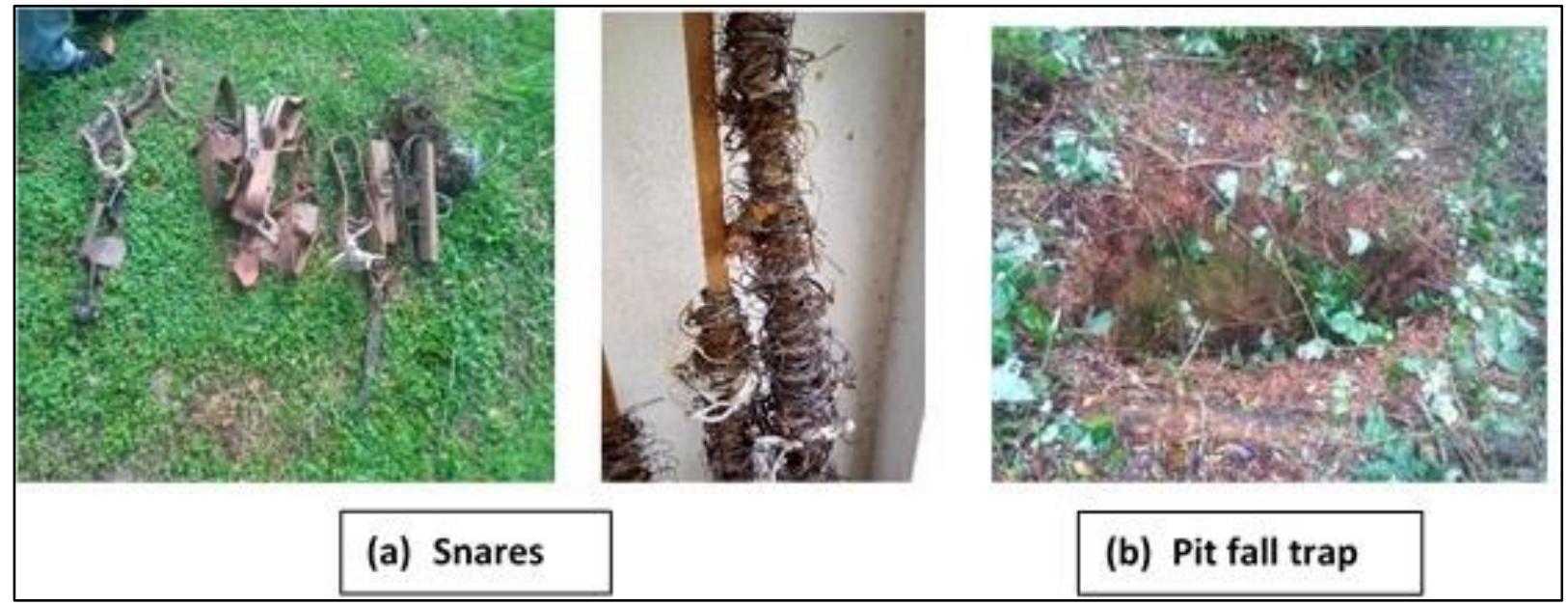

Additional threats to elephants in KNP was their exposure to harm during crop-raiding which leaves elephants vulnerable to poisoning and hostilities with the communities and negates support to KNP conservation. The expansion of land for agriculture (maize, tree farming) as well as human settlements 
very close to the protected area boundaries, results in more frequent conflicts with the adjacent community as was observed during this study (Figure 7a). Planting crops close to the boundaries entices the elephants to fill up the established trench barriers (Figure $7 b$ ) and cross to gardens to raid crops. This puts the mutual harmony between elephants the community at risk.

Figure 7: (a) Planting of attractive crops adjacent to the park and (b) subsequent damage of the barrier (trench) by elephants to cross and raid the crops.

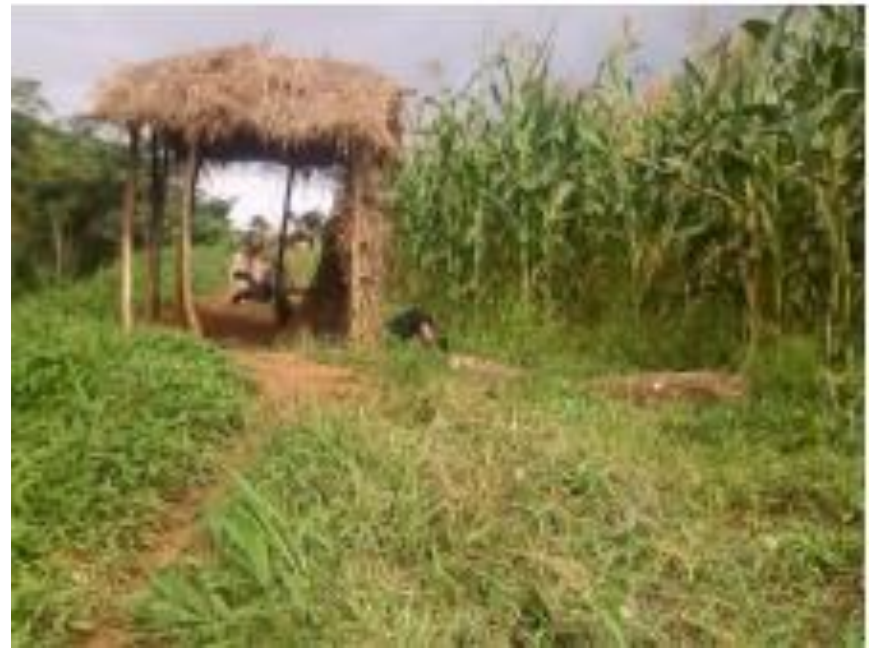

(a) Maize crop grown adjacent to KNP being guarded

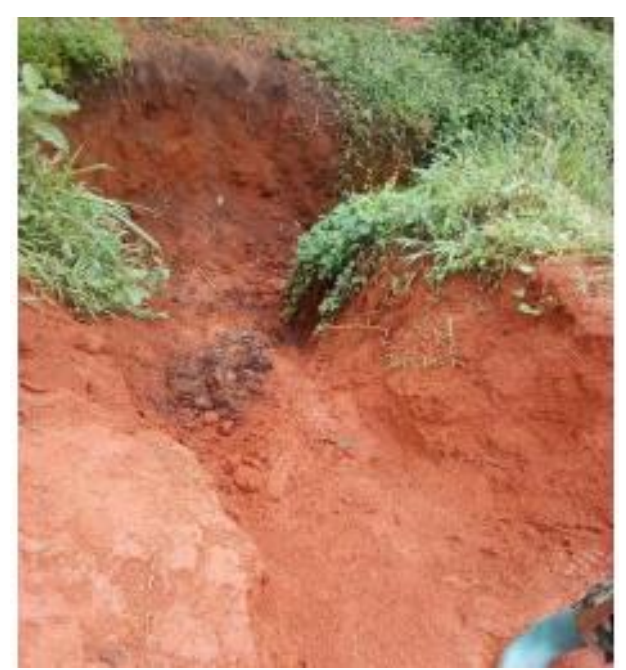

b) Trench damaged by elephants

\section{DISCUSSION}

The increased elephant population recorded in this study may be attributed to the general improved political stability in Uganda and the better park management efforts by UWA. The better security coupled with improved management interventions provides favourable conditions and opportunities for the elephant populations in KNP to increase. The elephant population reduction from 1970 to the 1980s could be attributed to poaching for ivory and poor law enforcement during the time of political turbulence experienced from 1972 to 1986. This could have resulted in very few breeding adults. Social stress from poaching is also an important variable influencing the reproductive output (Laws et al., 1975). Elephants are slow breeding with long inter-birth intervals, gestation periods, and offspring dependency (Lahdenperä et al., 2016) as such they are more vulnerable to population setbacks as it takes longer time for them to recover. Their growth rates are also very low and thus have little potential for rapid recovery following population disruption (Kangwana, 1996a).

The elephant population in Kibale National Park (KNP) is currently subjected to seasonal increase due to immigration from the neighbouring Queen Elizabeth National Park (QENP) through the Dura corridor which was established to link KNP to QENP. Any seasonal variations in the population of KNP elephants may therefore be explained by in and out movements between KNP and QENP through the Dura corridor. This is because elephants have been reported to traverse protected areas including QENP and Virunga National Park, Democratic Republic of Congo (such as reported in the Independent newspaper of Jan $29^{\text {th }}-4^{\text {th }}$ Feb 2021) probably reaching KNP as also reported by Keigwin et al. (2016). This implies the population of elephants in Kibale may not be static and movements in and out of KNP can be reflected in seasonal variation in numbers. Monitoring elephant population changes is very vital for measuring the effectiveness of conservation interventions (Wanyama et al., 2010). For example, during fruiting seasons elephants tend to move into the close canopy forests looking for the fruits of trees such as Balanities wilsoniana which were abundant but restricted to close forest habitats (Chapman et al. 1992). During the non-fruiting season, they then move to the more open woodland/savanna or regenerating forest habitats within the patches in the

78 | This work is licensed under a Creative Commons Attribution 4.0 International License. 
forest which provide lush vegetation favourable for foraging. It is important to continuously monitor the elephant population and use the population dynamics and the ecosystem knowledge to institute steps to avoid any challenges likely to cause changes to the ecosystem as a whole.

This study confirmed that elephants in KNP were widely distributed in the park, an indication of optimum use of the park habitat by elephants. Such movements reduce foraging pressure on the park's vegetation. The African elephant is a keystone species whose population changes can have a significant effect on ecosystem functioning and structure (Mpakairi et al., 2020). When elephant population increase beyond the carrying capacity of an ecosystem, it may influence ecosystem structure, woodland dynamics, and accelerated nutrient cycling. Its feeding habits may or may not be beneficial to other species (Rutina et al., 2005).

Elephants were the most commonly cited problem animal species causing widespread destruction to crops around KNP. However, Naughton-Treves (1998) reported that on average smaller mammal species such as red-tail monkeys cause more crop damage. In this study, there was evidence of the increase and spread of elephant populations to formerly un-visited areas which may have further implications for the planning of Human elephant conflict management interventions. Elephants sometimes cause severe damage at one go, and may lead to a large area of crops damaged. Under such scenarios, the elephants become the victims of retaliatory attacks as the elephants are injured or killed by individuals guarding crops (Hill, 2018). While there is an opportunity for any excess population to cross into the neighbouring QENP, there is a risk that the wide distribution may become associated with increased human-elephant conflicts across the park boundary. While there is currently minimal risk of wildlife poaching including elephants in KNP there is need for continual development of mitigation measures to reduce HEC around the park.

\section{CONCLUSION}

There is an increase in the population of elephants in KNP. This coupled with wide distribution may result in increased Human-elephant conflicts. The Park management and stakeholders are already implementing diverse crop protection strategies targeting elephant problem animals. With the improved security around KNP, there is, however need to continue to search and develop innovative, longer-term, and sustainable solutions to humanwildlife conflicts since human-wildlife conflicts will continue to influence the success of conservation of biodiversity in the protected areas.

\section{ACKNOWLEDGMENTS}

This study was funded by Uganda Wildlife Authority (UWA). The fieldwork team consisted of UWA personnel in Kibale National Park and particularly Mr. Julius Mutokambali and Enyango Moses. Mr. Guma Nelson, and Mr. Agaba Hillary, the Conservation Area Manager and the warden Research and Monitoring for KNP, respectively were very instrumental in providing guidance and arranging logistics. The research team is also indebted to UWA Management for providing permission for entry to KNP. The research team is highly indebted to the staff at the Makerere University's Biological Field Station (MUBS) based at KNP who provided logistical support during the fieldwork.

\section{Author's contribution}

$\mathrm{AE}$ and $\mathrm{AD}$ conceptualized the research, designed the data collection tool and protocol and carried out the field data collection work, wrote and revised the article. Adriko Kennedy undertook GIS/RS-based data analysis and contributed to the revisions of the draft paper.

\section{Conflict of interest statement}

The authors have no conflict of interest in this study.

\section{Ethics Statement}

The research was conducted using observation of spoors of elephants (including dung, footprints, feeding signs among others). Permission was sought from the park management and other local authorities to undertake the study.

79 | This work is licensed under a Creative Commons Attribution 4.0 International License. 


\section{REFERENCES}

Barnes, B. V., Zak, D. R., Denton, S. R., \& Spurr, S. H. (1997). Forest ecology: John Wiley and Sons.

Barnes, R. (1993). Indirect methods of counting elephants in forest. Pachyderm (16), 24-33.

Barnes, R. F. W. (1996b). Estimating forest elephant abundance by dung counts. in $\mathrm{K}$. Kangwana, editor. Studying elephants: AWF Technical handbook 7. African Wildlife Foundation, Nairobi, Kenya.

Barnes, R. F. W., K. Beardsley, F. Michelmore, K. L. Barnes, M. P. T. Alers, and A. Blom (1997). "Estimating Forest Elephant Numbers with Dung Counts and a Geographic Information System." The Journal of Wildlife Management61, no. 4 (1997): 1384-93.

Barnes, R., \& Jensen, K. (1987). How to count elephants in forests Elephant and Rhino Specialist Group Tech. (pp. 1-6.): Bull.

Buckland, S., \& Elston, D. (1993). Empirical models for the spatial distribution of wildlife. Journal of Applied Ecology, 478-495.

Byaruhanga, A. (2001). Important bird areas in Uganda: Nature Uganda, the East African Natural History Society.

Campos-Arceiz, A., \& Blake, S. (2011). Megagardeners of the forest-the role of elephants in seed dispersal. Acta Oecologica, 37(6), 542-553.

Chapman L.J, Ca. Chapman R. W Wrangham (1992). Balanities wilsoniana: elephant dependent dispersal? Journal of Tropical Ecology 8:275-283.

Fewster, R. M., Laake, J. L., \& Buckland, S. T. (2005). Line transect sampling in small and large regions. Biometrics, 61(3), 856-859.

Hedges, S., Johnson, A., Ahlering, M., Tyson, M., \& Eggert, L. S. (2013). Accuracy, precision, and cost-effectiveness of conventional dung density and fecal DNA based survey methods to estimate Asian elephant (Elephas maximus) population size and structure. Biological Conservation, 159, 101-108.

Hickey, J. R., Uzabaho, E., Akantorana, M., Arinaitwe, J., Bakebwa, I., Bitariho, R., Kayijamahe, C. (2019). Bwindi-Sarambwe 2018 Surveys.

Hill, C. M. (2018). Crop foraging, crop losses, and crop-raiding. Annual Review of Anthropology.

Hoare, R. (2012). Lessons from 15 years of humanelephant conflict mitigation: Management considerations involving biological, physical and governance issues in Africa. Pachyderm, 51, 60-74.

Howard, P. (1991). Nature conservation in Uganda's forest reserves. Gland, Switzerland.

IUCN (Producer). (2021). The IUCN red list of threatened species Retrieved from www.iucnredlist.org

Kangwana, K. (1996a). Assessing the impact of human-elephant interactions. Studying elephants, AWF technical handbook series, 138147.

Kangwana, K. (1996b). Studying Elephants, Technical Handbook Series No. 7. African Wildlife Foundation.

Keigwin, M., Wabukawo, V., Wasser, S., \& Chapman, C. (2016). Impacts on transboundary elephant movements between Queen Elizabeth Conservation Area, Uganda and Parc National des Virunga, Democratic Republic of Congo. Pachyderm, 57, 118-121.

Laake, J., Buckland, S., Anderson, D., \& Burnham, K. (1994). DISTANCE users guide: version 2.1. Colorado Cooperative Fish and Wildlife Research Unit, Colorado State University, Fort Collins, CO, 80523, 84.

Lahdenperä, M., Mar, K. U., \& Lummaa, V. (2016). Short-term and delayed effects of mother death on calf mortality in Asian elephants. Behavioral Ecology, 27(1), 166-174.

80 This work is licensed under a Creative Commons Attribution 4.0 International License. 
Laws, R. M., Parker, I. S., \& Johnstone, R. C. (1975). Elephants and their habitats: Clarendon Press.

McClanahan, T. (1986). Quick population survey method using faecal droppings and a steady state assumption. African Journal of Ecology, 24(1), 37-39.

Mpakairi, K. S., Ndaimani, H., Tagwireyi, P., Zvidzai, M., \& Madiri, T. H. (2020). Futuristic climate change scenario predicts a shrinking habitat for the African elephant (Loxodonta africana): evidence from Hwange National Park, Zimbabwe. European Journal of Wildlife Research, 66(1), 1-10.

Naughton, L., Rose, R., \& Treves, A. (1999). The social dimensions of human-elephant conflict in Africa: a literature review and case studies from Uganda and Cameroon. A Report to the African Elephant Specialist Group, Human-Elephant Conflict Task Force, IUCN, Glands, Switzerland.

Naughton-Treves, L. (1998). Predicting patterns of crop damage by wildlife around Kibale National Park, Uganda. Conservation biology, 12(1), 156168.

Norton-Griffiths, M. (1978). Counting animals: Serengeti Ecological Monitoring Programme, African Wildlife Leadership.

Rutina, L. P., Moe, S. R., \& Swenson, J. E. (2005). Elephant Loxodonta africana driven woodland conversion to shrubland improves dry-season browse availability for impalas Aepyceros melampus. Wildlife Biology, 11(3), 207-213.

Struhsaker, T., \& Ting, N. (2020). Piliocolobus tephrosceles. The IUCN Red List of Threatened Species 2020: e. T18256A92661680.

Uganda Wildlife Authority UWA). (2005). Ground census of mammals in Kibale National Park. Report, Kampala, Uganda.

UWA. (2016). The Elephant Conservation Action Plan for Uganda 2016-2026 The Elephant Conservation Action Plan for Uganda 20162026 (pp. 119-128): UWA.
Vanleeuwe, H. (2010). Predictive mapping of season distributions of large mammals using GIS: an application to elephants on Mount Kenya. Methods in Ecology and Evolution, 1(2), 212-220.

Wanyama, F., Muhabwe, R., Plumptre, A. J., Chapman, C. A., \& Rothman, J. M. (2010). Censusing large mammals in Kibale National Park: evaluation of the intensity of sampling required to determine change. African Journal of Ecology, 48(4), 953-961.

Wing, L. D., \& Buss, I. O. (1970). Elephants and forests. Wildlife monographs, (19), 3-92.

81 This work is licensed under a Creative Commons Attribution 4.0 International License. 